\title{
A Comparative Study of Radiolabeled Bombesin Analogs for the PET Imaging of Prostate Cancer
}

\author{
Yang $\mathrm{Liu}^{1,2}$, Xiang $\mathrm{Hu}^{2}$, Hongguang $\mathrm{Liu}^{2}$, Lihong $\mathrm{Bu}^{2}$, Xiaowei $\mathrm{Ma}^{2}$, Kai Cheng ${ }^{2}$, Jinbo $\mathrm{Li}^{2}$, Mei Tian ${ }^{1}$, Hong Zhang ${ }^{1}$, \\ and Zhen Cheng ${ }^{2}$ \\ ${ }^{I}$ Department of Nuclear Medicine, Second Affiliated Hospital of Zhejiang University School of Medicine, Institute of Nuclear \\ Medicine and Molecular Imaging of Zhejiang University, Center of Excellence in Medical Molecular Imaging of Zhejiang State, \\ Hangzhou, China; and ${ }^{2}$ Molecular Imaging Program at Stanford (MIPS), Department of Radiology, Bio-X Program, Canary Center \\ at Stanford for Cancer Early Detection, Stanford University, Stanford, California
}

Radiolabeled bombesin (BBN) analogs that bind to the gastrin-releasing peptide receptor (GRPR) represent a topic of active investigation for the development of molecular probes for PET or SPECT of prostate cancer (PCa). RM1 and AMBA have been identified as the 2 most promising BBN peptides for GRPR-targeted cancer imaging and therapy. In this study, to develop a clinically translatable BBN-based PET probe, we synthesized and evaluated ${ }^{18} \mathrm{~F}$-AIF- (aluminum-fluoride) and ${ }^{64} \mathrm{Cu}$-radiolabeled RM1 and AMBA analogs for their potential application in PET imaging of PCa. Methods: 1,4,7-triazacyclononane, 1-glutaric acid-4,7 acetic acid (NODAGA)-conjugated RM1 and AMBA were synthesized and tested for their GRPR-binding affinities. The NODAGA-RM1 and NODAGA-AMBA probes were further radiolabeled with ${ }^{64} \mathrm{Cu}$ or ${ }^{18} \mathrm{~F}$-AIF and then evaluated in a subcutaneous PCa xenograft model (PC3) by small-animal PET imaging and biodistribution studies. Results: NODAGA-RM1 and NODAGA-AMBA can be successfully synthesized and radiolabeled with ${ }^{64} \mathrm{Cu}$ and ${ }^{18} \mathrm{~F}$-AIF. ${ }^{64} \mathrm{Cu}$ - and ${ }^{18} \mathrm{~F}$-AIF-labeled NODAGA-RM1 demonstrated excellent serum stability and tumor-imaging properties in the in vitro stability assays and in vivo imaging studies. ${ }^{64} \mathrm{Cu}-\mathrm{NODAGA}-\mathrm{RM} 1$ exhibited tumor uptake values of $3.3 \pm 0.38,3.0 \pm 0.76$, and $3.5 \pm$ 1.0 percentage injected dose per gram of tissue $(\% \mathrm{ID} / \mathrm{g})$ at $0.5,1.5$, and $4 \mathrm{~h}$ after injection, respectively. ${ }^{18} \mathrm{~F}-A \mathrm{~F}-\mathrm{NODAGA}-\mathrm{RM} 1 \mathrm{exhibited}$ tumor uptake values of $4.6 \pm 1.5,4.0 \pm 0.87$, and $3.9 \pm 0.48 \% \mathrm{ID} / \mathrm{g}$ at $0.5,1$, and $2 \mathrm{~h}$, respectively. Conclusion: The high-stability, efficient tumor uptake and optimal pharmacokinetic properties highlight ${ }^{18} \mathrm{~F}$ AIF-NODAGA-RM1 as a probe with great potential and clinical application for the PET imaging of prostate cancer.

Key Words: ${ }^{18} \mathrm{~F}-A I F ;$ bombesin; GRPR; prostate cancer; PET

J Nucl Med 2013; 54:2132-2138

DOI: $10.2967 /$ jnumed.113.121533

Received Feb. 11, 2013; revision accepted Aug. 2, 2013.

For correspondence or reprints contact either of the following:

Zhen Cheng, Molecular Imaging Program at Stanford, Canary Center at Stanford for Cancer Early Detection, Department of Radiology and Bio-X Program, 1201 Welch Rd., Lucas Expansion, P095, Stanford University, Stanford, CA 94305.

E-mail: zcheng@stanford.edu

Hong Zhang, Department of Nuclear Medicine, Second Affiliated Hospital of Zhejiang University School of Medicine, Institute of Nuclear Medicine and Molecular Imaging, Zhejiang University, Center of Excellence in Medical Molecular Imaging of Zhejiang State, 88 Jiefang Rd., Hangzhou, Zhejiang 310009, China.

E-mail: hzhang21@gmail.com

Published online Nov. 6, 2013.

COPYRIGHT (C) 2013 by the Society of Nuclear Medicine and Molecular Imaging, Inc.
$\mathbf{P}$ death in men in death in men in the United States (1). Conventional imaging techniques (e.g., CT) have played a relatively minor role in the management of organ-confined $\mathrm{PCa}$, and novel imaging techniques including PET could play an important role in the detection of localized and locally recurrent PCa (2). It is crucial to develop novel imaging probes and techniques for the primary diagnosis, follow-up, and monitoring of the recurrence of PCa. The clinical evaluation of certain PET probes, such as ${ }^{18} \mathrm{~F}-\mathrm{FDG}$ and radiolabeled acetate and choline, has highlighted the pivotal role that PET might play in the imaging and characterization of PCa patients. The discovery of novel PET molecular probes is expected to dramatically facilitate the diagnosis, prognosis, and stratification of PCa patients for effective therapeutic regimens (3-8).

Serum prostate-specific antigen testing has been a valuable tool in the detection, staging, and monitoring of $\mathrm{PCa}$, but lack of specificity results in a high negative biopsy rate. Some biomarkers with high specificity for the disease in tissue have been identified, such as the gastrin-releasing peptide receptor (GRPR). Because it takes advantage of highly sensitive molecular imaging methods such as PET, GRPR-targeted PET imaging can be used for the detection, staging, and monitoring of PCa in a noninvasive and specific manner. GRPR is overexpressed in many human epithelial malignancies, including PCa $(9,10)$, breast cancer (11), and lung cancer (12). GRPR-binding ligands represent potential diagnostic and therapeutic agents for the targeting of GRPR-positive tumors. Examples of such GRPR-binding ligands include mammalian gastrin-releasing peptide (GRP) and its amphibian homolog bombesin (BBN) (13). These 2 peptides share homology in a C-terminal region, $\mathrm{BBN}(7-14)$, which is composed of the following 8 amino acid residues: Gln-Trp-Ala-Val-Gly-His-Leu-Met-NH 2 . BBN(7-14) has been extensively used for the development of molecular probes for the imaging of PCa (14-19). Moreover, a variety of BBN analogs, including both agonists and antagonists, has been radiolabeled with different radionuclides for GRPR-targeted PCa imaging and therapy (20-28).

Among those GRPR-targeted peptides, RM1 (DOTA-CH ${ }_{2} \mathrm{CO}-$ G-4-aminobenzoyl-f-W-A-V-G-H-Sta-L- $\mathrm{NH}_{2}$, antagonist) (24) and AMBA (DOTA- $\mathrm{CH}_{2} \mathrm{CO}-\mathrm{G}-4$-aminobenzoyl-Q-W-A-V-G-H-L-M$\mathrm{NH}_{2}$, agonist) (23) have been shown to be 2 promising GRPRtargeted peptide platforms for developing imaging and therapeutic agents for PCa. These 2 peptides have been radiolabeled with radiometals $\left({ }^{111} \mathrm{In},{ }^{68} \mathrm{Ga}\right.$, and $\left.{ }^{64} \mathrm{Cu}\right)$ for SPECT and PET imaging of PCa (24-27). AMBA has also been radiolabeled with ${ }^{177} \mathrm{Lu}$ for 
radionuclide therapy of $\mathrm{PCa}(23,28)$. All of these radiocomplexes exhibit efficient tumor accumulation and favorable in vivo properties, which support their potential clinical application. More interestingly, ${ }^{68} \mathrm{Ga}$-AMBA-based PET imaging has recently been found to be superior to metabolism-based imaging using ${ }^{18} \mathrm{~F}$ methylcholine for scintigraphy of PCa (25). These studies clearly suggest that the increased likelihood of successfully translating a BBN probe into the clinic can be achieved using AMBA and RM1 scaffolds.

However, ${ }^{18}$ F-labeled RM1 and AMBA have not been explored, and currently there are no published data providing a head-to-head comparison of the performance of ${ }^{18} \mathrm{~F}$-labeled RM1 and AMBA analogs. ${ }^{18} \mathrm{~F}$ is the most widely used radionuclide for clinical PET because of its ideal physical properties ( $\sim 100 \%$ positron efficiency, low $\beta+$ energy [0.64 MeV], and physical half-life of $109.7 \mathrm{~min}$ ). Moreover, ${ }^{64} \mathrm{Cu}$ has also gained extensive interest in the context of PET probe development and has been actively explored to label peptides for clinical imaging because of its many advantages including simple radiolabeling chemistry. Compared with ${ }^{18} \mathrm{~F}$, however, ${ }^{64} \mathrm{Cu}$ suffers from lower availability, longer half-life, and potential higher radiation dose (29). In this study, we synthesized 1,4,7-triazacyclononane,1-glutaric acid-4,7-acetic acid (NODAGA)conjugated RM1 and AMBA (NODAGA-RM1, NODAGA-AMBA) peptides and then radiolabeled them via a simple 1-step chelation reaction $\left({ }^{18} \mathrm{~F}-\mathrm{AlF}\right.$ [aluminum-fluoride] or $\left.{ }^{64} \mathrm{Cu}\right)$ in aqueous phase (30-33) to generate ${ }^{18} \mathrm{~F}-\mathrm{AlF}-\mathrm{NODAGA}-\mathrm{RM} 1,{ }^{18} \mathrm{~F}$-AIF-NODAGAAMBA, ${ }^{64} \mathrm{Cu}-\mathrm{NODAGA}-\mathrm{RM} 1$, and ${ }^{64} \mathrm{Cu}-\mathrm{NODAGA}-A M B A$ (Fig. 1). We further evaluated these PET probes and compared them headto-head in PC3 tumor-bearing mice.

\section{MATERIALS AND METHODS}

All of the chemicals obtained commercially were of analytic grade and used without further purification. The PC3 human prostate carcinoma cell line was obtained from the American Type Culture Collection. Male nude mice were purchased from the Charles River Laboratory. ${ }^{64} \mathrm{Cu}$ was provided by the Department of Medical Physics, University of Wisconsin at Madison. No-carrier-added ${ }^{18} \mathrm{~F}$ was obtained from an in-house PETtrace cyclotron (GE Healthcare). The Sep-Pak C18 cartridges were obtained from Waters. The syringe filters and polyethersulfone membranes (pore size, $0.22 \mu \mathrm{m}$; diameter, $13 \mathrm{~mm}$ ) were obtained from Nalgene Nunc International. ${ }^{125} \mathrm{I}-\left[\mathrm{Tyr}^{4}\right] \mathrm{BBN}$ was purchased from PerkinElmer. 2,2' -(7-(1-carboxy-4-((2,5-dioxopyrrolidin1-yl)oxy)-4-oxobutyl)-1,4,7-triazonane-1,4-diyl)diacetic acid (NOTAGANHS) was purchased from CheMatech.

Reversed-phase high-performance liquid chromatography (HPLC) was performed using a Dionex 680 chromatography system with a UVD 170U absorbance detector and 105S single-channel model radiation detector (Carroll \& Ramsey Associates). A Vydac protein and peptide column (218TP510; C18, $5 \mu \mathrm{m}, 250 \times 10 \mathrm{~mm}$ ) was used for semipreparative HPLC at a flow rate of $4 \mathrm{~mL} / \mathrm{min}$. The mobile phase was maintained at a constant $95 \%$ for solvent A $(0.1 \%$ trifluoroacetic acid [TFA] in water) and 5\% for solvent $\mathrm{B}(0.1 \%$ TFA in acetonitrile [MeCN]) at $0-5 \mathrm{~min}$ and was subsequently changed to $35 \%$ for solvent $\mathrm{A}$ and $65 \%$ for solvent $\mathrm{B}$ at $35 \mathrm{~min}$. A Vydac protein and peptide column (218TP510; C18, $5 \mu \mathrm{m}, 250 \times 4.6 \mathrm{~mm}$ ) was used for the analytic HPLC at a flow rate of $1 \mathrm{~mL} / \mathrm{min}$. The mobile phase was changed from an initial 95\% for solvent $\mathrm{A}$ and $5 \%$ for B (from 0 to $2 \mathrm{~min}$ ) to $35 \%$ for solvent $\mathrm{A}$ and $65 \%$ for solvent $\mathrm{B}$ at $32 \mathrm{~min}$. The recorded data were processed using Chromeleon software (version 6.50; Dionex). The ultraviolet absorbance was monitored at $218 \mathrm{~nm}$, and the identification of the peptides was confirmed based on the ultraviolet spectrum using a PDA detector (Dionex).

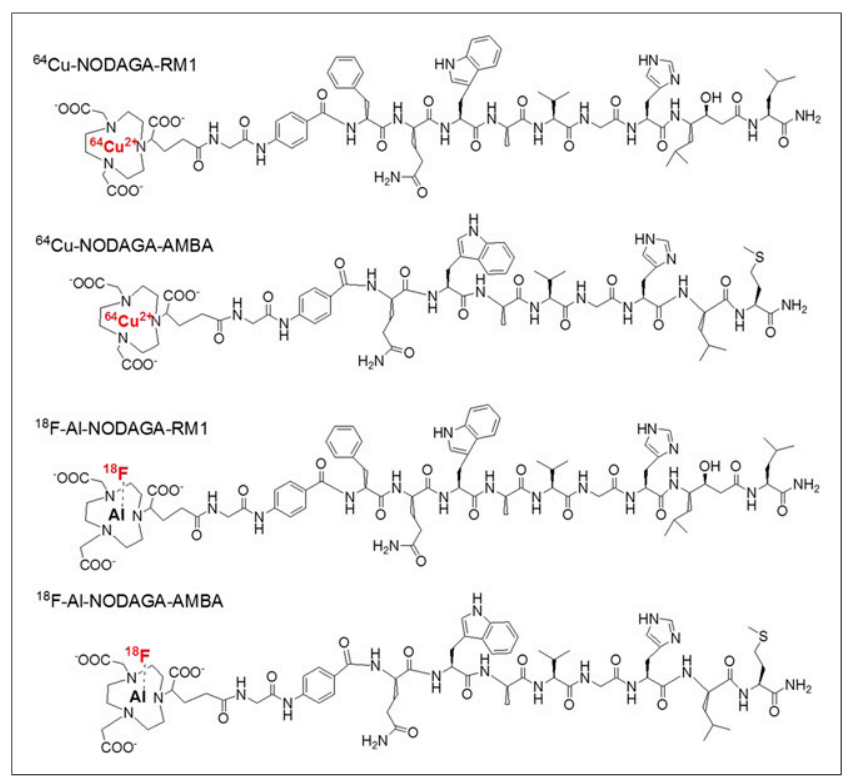

FIGURE 1. Schematic structures of ${ }^{64} \mathrm{Cu}-\mathrm{NODAGA-RM1,}{ }^{64} \mathrm{Cu}-\mathrm{NODAGA}-$ AMBA, ${ }^{18}$ F-AIF-NODAGA-RM1, and ${ }^{18}$ F-AIF-NODAGA-AMBA.

\section{Chemistry and Radiochemistry}

Preparation of NODAGA-RM1 and NODAGA-AMBA. The G-4aminobenzoyl-Gln-Trp-Ala-Val-Gly-His-Leu-Met- $\mathrm{NH}_{2}$ (abbreviated as AMBA) and G-4-aminobenzoyl-D-Phe-Gln-Trp-Ala-Val-Gly-His-StaLeu- $\mathrm{NH}_{2}$ (abbreviated as RM1) peptides (Fig. 1) were synthesized. Then the 2 peptides were conjugated with NODAGA-NHS to obtain NODAGA-AMBA and NODAGA-RM1, respectively. The detailed procedures are described in the supplemental file (supplemental materials are available at http://jnm.snmjournals.org).

${ }^{64} \mathrm{Cu}$ and ${ }^{18} \mathrm{~F}$ Labeling. The ${ }^{64} \mathrm{Cu}$ labeling was performed as previously described (34). Briefly, NODAGA-RM1 or NODAGA-AMBA (2 nmol each) was dissolved in NaOAc buffer (0.1 M, pH 5.0) and labeled with ${ }^{64} \mathrm{Cu}(74 \mathrm{MBq}$ [2 $\left.\mathrm{mCi}]\right)$ for $60 \mathrm{~min}$ at $37^{\circ} \mathrm{C}$. The labeled peptides were then purified by analytic HPLC. The radioactive peaks containing the desired products were collected and rotary-evaporated to remove the solvent. The products were then formulated in phosphate-buffered saline ( $1 \times, \mathrm{pH} 7.4)$ and passed through a $0.22-\mu \mathrm{m}$ Millipore filter into a sterile vial for the subsequent in vitro and in vivo experiments. The labeling yield was above $90 \%$ for all of the probes.

The ${ }^{18} \mathrm{~F}$-AlF labeling was performed as previously described (33). A QMA SepPak Light cartridge (Waters) fixed with ${ }^{18} \mathrm{~F}(1.1 \mathrm{GBq}[30 \mathrm{mCi}])$ was washed with $2.5 \mathrm{~mL}$ of metal-free water. The ${ }^{18} \mathrm{~F}$ was then eluted from the cartridge with $400 \mu \mathrm{L}$ of $0.4 \mathrm{M} \mathrm{KHCO}_{3}$, from which $200-\mu \mathrm{L}$ fractions were taken. The $\mathrm{pH}$ of the solution was adjusted to 4 with metal-free glacial acetic acid. $\mathrm{AlCl}_{3}(2 \mathrm{mM}, 3 \mu \mathrm{L})$ in $0.1 \mathrm{M}$ sodium acetate buffer (pH4) and $10 \mu \mathrm{L}$ of peptide ( $1 \mathrm{mg} / \mathrm{mL}$ in dimethyl sulfoxide) were then added to the reaction solution sequentially. The reaction mixtures were incubated at $100^{\circ} \mathrm{C}$ for $15 \mathrm{~min}$. The labeled peptides were then purified by semipreparative HPLC. The fractions containing the desired products were collected and rotary-evaporated to remove the solvent. The products were reconstituted in phosphate-buffered saline and passed through a $0.22-\mu \mathrm{m}$ Millipore filter into sterile vials for the subsequent in vitro and in vivo experiments.

\section{Cell-Binding Assays}

The cell-binding assay was performed similarly as previously reported $(19,35)$. The detailed procedures are included in the supplemental file.

\section{Mouse Serum Stability}

The in vitro stability of the PET probes was evaluated by incubation with mouse serum $(1 \mathrm{~mL})$ at $37^{\circ} \mathrm{C}$. The solutions were filtered using 
a NanoSep $10 \mathrm{~K}$ centrifuge (Pall Corp.) to isolate low-molecular-weight radiocomplexes. The samples were analyzed by the radio-HPLC, and the percentages of intact PET probe were determined by quantifying the peaks corresponding with the intact probe and degradation products.

\section{Small-Animal PET Imaging}

The animal procedures were performed according to a protocol approved by the Stanford University Institutional Animal Care and Use Committee. The establishment of the PC3 tumor mice model and the procedure for small-animal PET are shown in the supplemental file.

The PC3 xenograft-bearing mice were injected with approximately $1.85 \mathrm{MBq}(50 \mu \mathrm{Ci})$ of either ${ }^{64} \mathrm{Cu}-\mathrm{NODAGA}-\mathrm{RM} 1$ or ${ }^{64} \mathrm{Cu}-\mathrm{NODAGA}-$ AMBA via the tail vein ( $n=4$ for each group). At the indicated times after injection $(0.5,1.5$, and $4 \mathrm{~h})$, the mice were anesthetized with isoflurane (5\% for induction and $2 \%$ for maintenance in $100 \% \mathrm{O}_{2}$ ) using a knock-down box. Five-minute static scans were then obtained. The PC3 xenograft-bearing mice were injected with $0.37 \mathrm{MBq}(10$ $\mu \mathrm{Ci}$ ) of either ${ }^{18} \mathrm{~F}$-AlF-NODAGA-RM1 or ${ }^{18} \mathrm{~F}$-AlF-NODAGA-AMBA probe via the tail vein ( $n=5$ for each group). Blocking studies were performed via tail vein injection of the ${ }^{18} \mathrm{~F}$ probe with cold AMBA (10 $\mathrm{mg} / \mathrm{kg}$ of body weight $)(n=5)$. At $0.5,1$, and $2 \mathrm{~h}$ after injection, the small-animal PET images were obtained.

The small-animal PET images were reconstructed using the 2dimensional ordered-subsets expectation maximization algorithm. No background correction was performed. The regions of interest (ROIs; 5 pixels for coronal and transaxial slices) were designated over the tumor on decay-corrected whole-body coronal images. The maximum counts per pixel per minute were obtained from the ROIs and converted to counts per milliliter per minute using a calibration constant. On the basis of an assumed tissue density of $1 \mathrm{~g} / \mathrm{mL}$, the ROIs were converted to counts per gram per min. The image ROI-derived percentage of the injected radioactive doses per gram of tissue $(\% \mathrm{ID} / \mathrm{g}$ ) values were determined by dividing counts per gram per minute by injected dose. No attenuation correction was performed.

\section{Animal Biodistribution Studies}

The PC3 xenograft-bearing nude mice ( $n=4$ for each group) were injected with approximately $1.85 \mathrm{MBq}(50 \mu \mathrm{Ci})$ of ${ }^{64} \mathrm{Cu}$-AlF-NODAGARM1 via the tail vein and sacrificed at 2 and $24 \mathrm{~h}$ after injection. The tumor and normal tissues of interest were removed and weighed, and their levels of radioactivity were measured using a $\gamma$-counter. The uptake of radioactivity in the tumor and normal tissues was expressed as \% ID/g.

Similarly, PC3 xenograft-bearing nude mice ( $n=5$ for each group) were injected with approximately $0.37 \mathrm{MBq}(10 \mu \mathrm{Ci})$ of ${ }^{18} \mathrm{~F}-\mathrm{AlF}-$ NODAGA-RM1 via the tail vein and sacrificed at $2 \mathrm{~h}$ after injection. The ${ }^{18}$ F-AlF-NODAGA-RM1 blocking study was performed by coinjection of the probe with the AMBA peptide (10 mg/kg of body weight) via the tail vein.

\section{Statistical Analysis}

The quantitative data are expressed as the mean values $\pm \mathrm{SD}$. The mean values were compared using a 1-way ANOVA and Student $t$ test. $P$ values of less than 0.05 were considered statistically significant.

\section{RESULTS}

\section{Chemistry and Radiochemistry}

The G-4-aminobenzoyl-Gln-Trp-Ala-Val-Gly-His-Leu-Met- $\mathrm{NH}_{2}$ (chemical formula for $[\mathrm{M}+\mathrm{H}]^{+}: \mathrm{C}_{64} \mathrm{H}_{88} \mathrm{~N}_{16} \mathrm{O}_{13}{ }^{+}$; calculated molecular weight [MW], 1,289.7 Da; measured MW, 1,289.6 Da) and G-4-aminobenzoyl-D-Phe-Gln-Trp-Ala-Val-Gly-His-Sta-Leu- $\mathrm{NH}_{2}$ (chemical formula for $[\mathrm{M}+\mathrm{H}]^{+}: \mathrm{C}_{53} \mathrm{H}_{73} \mathrm{~N}_{15} \mathrm{O}_{11}{ }^{+}$; calculated MW, 1,116.5 Da; measured MW, 1,116.5 Da) peptides were synthesized successfully using a solid-phase peptide synthesizer. The NODAGA peptides were then prepared by direct conjugation of
NODAGA-NHS with AMBA or RM1, resulting in $80 \%$ yield and greater than $90 \%$ purity. Both HPLC and mass spectroscopy were used to confirm the identity of the product. The retention time of the purified NODAGA-RM1 was $25.6 \mathrm{~min}$, and the molecular mass was measured as $1,646.8 \mathrm{Da}$ for $[\mathrm{M}+\mathrm{H}]^{+}$(chemical formula: $\mathrm{C}_{79} \mathrm{H}_{112} \mathrm{~N}_{19} \mathrm{O}_{20}$; calculated MW, 1,646.8 Da). The retention time of NODAGA-AMBA was $21.2 \mathrm{~min}$, and the $\mathrm{m} / \mathrm{z}$ was measured as 1,473.7 Da for $[\mathrm{M}+\mathrm{H}]^{+}$(chemical formula: $\mathrm{C}_{67} \mathrm{H}_{97} \mathrm{~N}_{18} \mathrm{O}_{18} \mathrm{~S}$; calculated MW, 1,473.7 Da).

${ }^{64} \mathrm{Cu}-\mathrm{NODAGA}-\mathrm{RM} 1$ and ${ }^{64} \mathrm{Cu}-\mathrm{NODAGA}-\mathrm{AMBA}$ were synthesized in high yield $(>85 \%)$, and their specific activities were calculated as greater than $29.6 \mathrm{GBq} / \mu \mathrm{mol}(800 \mathrm{mCi} / \mu \mathrm{mol})$. The radiosynthesis of the ${ }^{18} \mathrm{~F}$-AlF-NODAGA-RM1 and ${ }^{18} \mathrm{~F}-\mathrm{AlF}$ NODAGA-AMBA was completed within $40 \mathrm{~min}$, with decay-corrected yields of $5.6 \% \pm 1.1 \%$ and $4.9 \% \pm 1.3 \%$, respectively, and the radiochemical purity of the probes was more than $95 \%$. The specific activities of the purified ${ }^{18} \mathrm{~F}$-AlF-NODAGA peptides were calculated as greater than $1.85 \mathrm{GBq} / \mu \mathrm{mol}(50 \mathrm{mCi} / \mu \mathrm{mol})$.

\section{Cell-Binding Affinity Assay}

The receptor-binding affinity assay results for the RM1, NODAGARM1, AMBA, and NODAGA-AMBA probes are shown in Figure 2. All of these peptides inhibited the GRPR binding of ${ }^{125} \mathrm{I}_{-}\left[\mathrm{Tyr}^{4}\right]$ $\mathrm{BBN}$ on the PC3 cells in a concentration-dependent manner. The half maximal inhibitory concentration values for RM1, NODAGARM1, AMBA, and NODAGA-AMBA were $0.25 \pm 0.04,4.6 \pm 1.0$, $0.17 \pm 0.07$, and $1.9 \pm 0.50 \mathrm{nM}(n=4)$, respectively. These results suggest that the incorporation of the NODAGA motif reduced the GRPR-binding affinity of the original peptides but that the resulting bioconjugates still possessed significantly high affinities, warranting further biologic evaluation.

\section{Serum Stability of Radiolabeled NODAGA Peptides}

Both ${ }^{64} \mathrm{Cu}$-NODAGA-RM1 and ${ }^{18} \mathrm{~F}$-AlF-NODAGA-RM1 exhibited favorable stability in mouse serum. More than $90 \%$ of the probes remained intact after $1 \mathrm{~h}$ of incubation in mouse serum at $37^{\circ} \mathrm{C}$. However, ${ }^{64} \mathrm{Cu}$-NODAGA-AMBA and ${ }^{18} \mathrm{~F}$-AlF-NODAGA-AMBA exhibited degradation under the same conditions (supplemental data).

\section{Small-Animal PET Imaging Studies}

Representative decay-corrected coronal images of static scans at different time points after injection are shown in Figures 3-5. The PC3 tumors were clearly visualized using all of the PET

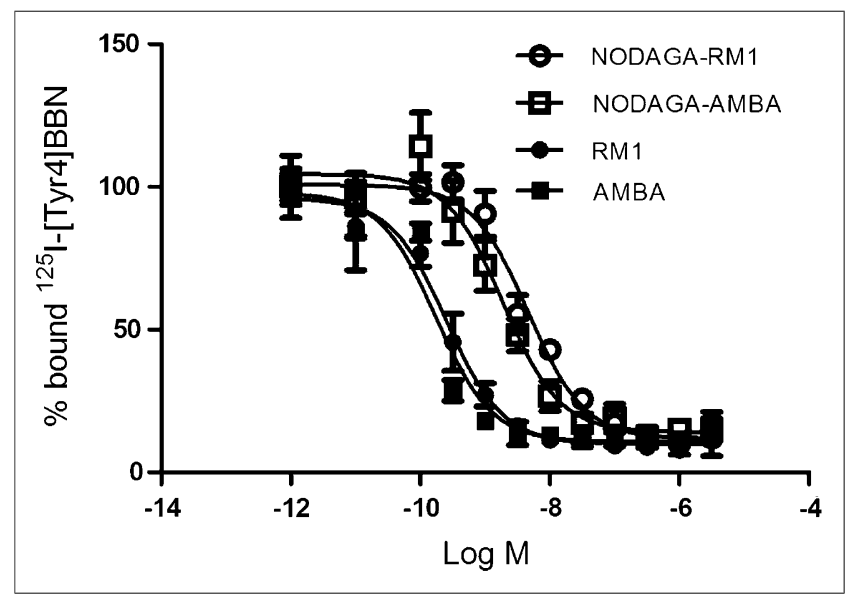

FIGURE 2. Inhibition of GRPR-binding by ${ }^{125}$-[Tyr4]BBN on PC3 cells by RM1, NODAGA-RM1, AMBA, and NODAGA-AMBA $(n=4$, mean \pm SD). 


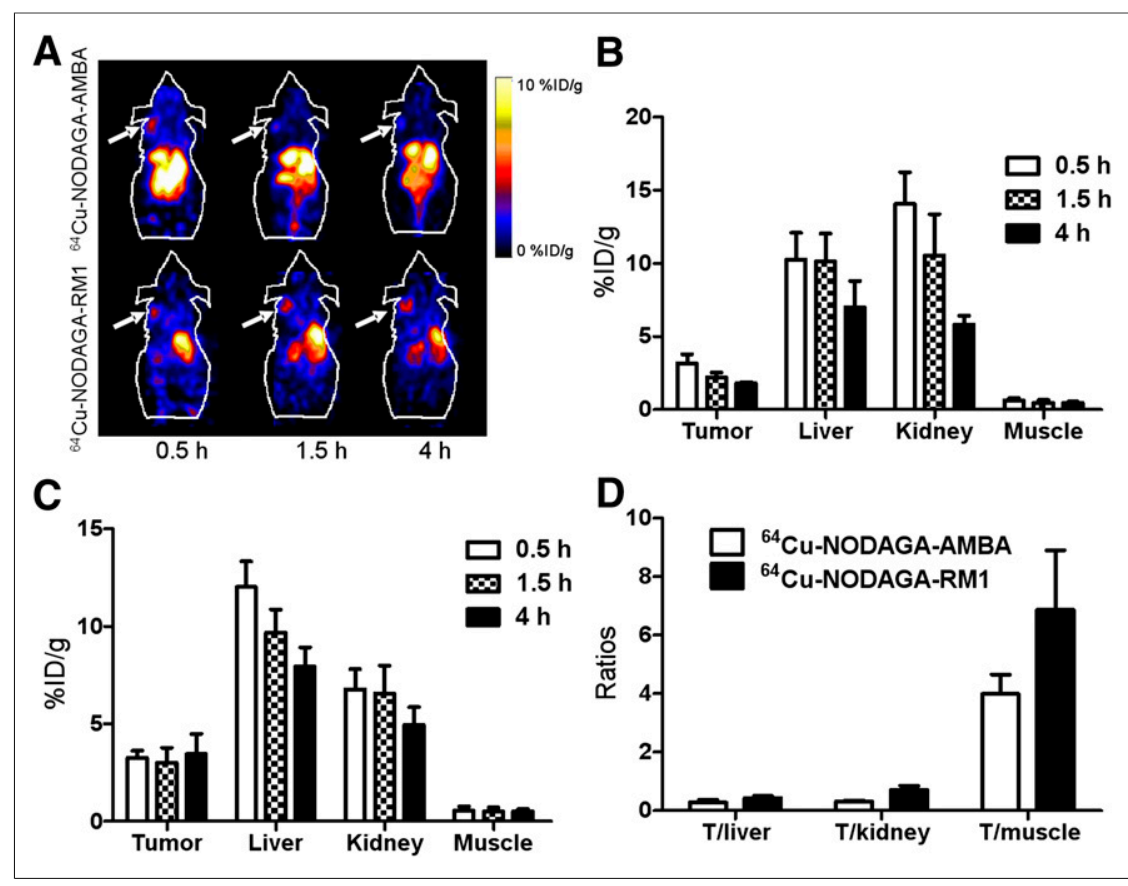

FIGURE 3. (A) Decay-corrected whole-body coronal small-animal PET images of PC3 tumorbearing male nude mice from static scan at $0.5,1.5$, and $4 \mathrm{~h}$ after injection of ${ }^{64} \mathrm{Cu}-\mathrm{NODAGA}-$ AMBA and ${ }^{64} \mathrm{Cu}-\mathrm{NODAGA}-\mathrm{RM} 1$. Tumors are indicated by arrows. (B and C) Small-animal PET quantification of tumors and major organs at $0.5,1.5$, and $4 \mathrm{~h}$ after injection of ${ }^{64} \mathrm{Cu}-\mathrm{NODAGA}$ AMBA (B) or ${ }^{64} \mathrm{Cu}-\mathrm{NOTAGA}-\mathrm{RM} 1$ (C). (D) Comparison of tumor-to-normal-tissue (muscle, kidney, and liver) ratios of ${ }^{64} \mathrm{Cu}-\mathrm{NODAGA}-\mathrm{RM} 1$ and ${ }^{64} \mathrm{Cu}-\mathrm{NODAGA}-\mathrm{AMBA}$ at $4 \mathrm{~h}$ after injection.

probes. The PC3 tumors were visualized using ${ }^{64} \mathrm{Cu}-\mathrm{NODAGA}-$ $\mathrm{RM} 1$ and ${ }^{64} \mathrm{Cu}-\mathrm{NODAGA}-\mathrm{AMBA}$, with favorable tumor-to-background contrast, even at $0.5 \mathrm{~h}$ (Fig. 3A). Interestingly, ${ }^{64} \mathrm{Cu}-\mathrm{NODAGA}-\mathrm{RM} 1$ exhibited persistent accumulation within the tumor until $4 \mathrm{~h}$ after

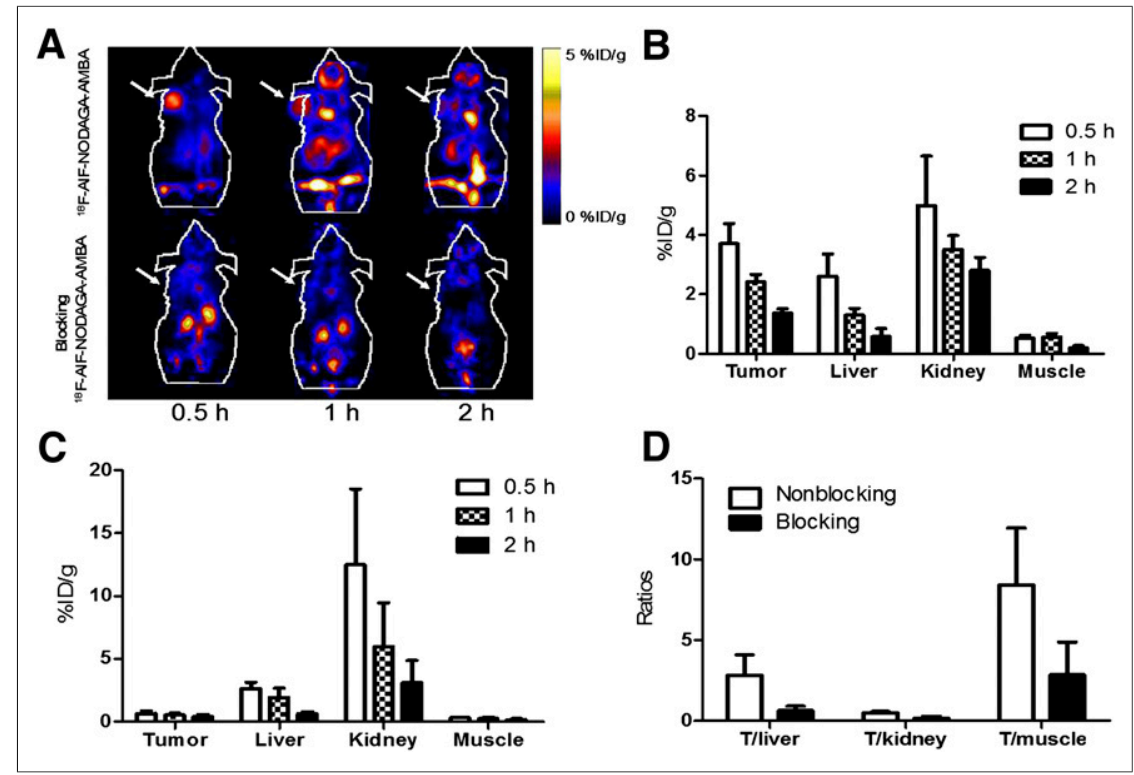

FIGURE 4. (A) Decay-corrected whole-body coronal small-animal PET images of PC3 tumorbearing male nude mice from static scan at $0.5,1$, and $2 \mathrm{~h}$ after injection of ${ }^{18} \mathrm{~F}$-AIF-NODAGA-AMBA without (top) or with (bottom) coinjection of AMBA as blocking agent (10 mg/kg of body weight). Tumors are indicated by arrows. (B and C) Small-animal PET image quantification of tumors and major organs at $0.5,1$, and $2 \mathrm{~h}$ after injection of ${ }^{18} \mathrm{~F}$-AIF-NODAGA-AMBA without (B) or with (C) AMBA as blocking agent $(10 \mathrm{mg} / \mathrm{kg}$ of body weight). (D) Comparison of tumor-to-normal-tissue (muscle, kidney, and liver) ratios of ${ }^{18}$ F-AIF-NODAGA-AMBA without or with AMBA at $2 \mathrm{~h}$ after injection. injection, whereas ${ }^{64} \mathrm{Cu}-\mathrm{NODAGA}-\mathrm{AMBA}$ exhibited more rapid tumor clearance and significantly reduced signal within the tumor at $4 \mathrm{~h}$ after injection. Further image quantification analysis confirmed the visualization results. The uptake of ${ }^{64} \mathrm{Cu}-$ NODAGA-RM1 within the PC3 tumors was $3.3 \pm 0.38,3.0 \pm 0.76$, and $3.5 \pm$ $1.0 \% \mathrm{ID} / \mathrm{g}$ at $0.5,1.5$, and $4 \mathrm{~h}$ after injection, respectively. In contrast, ${ }^{64} \mathrm{Cu}$ NODAGA-AMBA exhibited only $3.2 \pm$ $0.60,2.2 \pm 0.33$, and $1.8 \pm 0.10 \% \mathrm{ID} / \mathrm{g}$ tumor uptake at $0.5,1.5$, and $4 \mathrm{~h}$ after injection, respectively (Figs. 3B and 3C). Moreover, both PET probes exhibited significant accumulation in both the liver and the kidneys $(>10 \% \mathrm{ID} / \mathrm{g})$, indicating their clearance through both the hepatobiliary and the renal systems. Quantification analysis also revealed that ${ }^{64} \mathrm{Cu}$-NODAGA-RM1 exhibited significantly reduced kidney uptake at 0.5 and $1.5 \mathrm{~h}$, compared with ${ }^{64} \mathrm{Cu}-$ NODAGA-AMBA $(P<0.05)$, whereas no significant differences were observed between their levels of either kidney uptake at $4 \mathrm{~h}$ after injection or liver uptake at all of the time points (Figs. 3B and 3C). Increased tumor-to-normal-tissue ratios (tumor to liver, tumor to kidney, and tumor to muscle) were observed for ${ }^{64} \mathrm{Cu}-\mathrm{NODAGA}-\mathrm{RM} 1$, compared with those for ${ }^{64} \mathrm{Cu}-\mathrm{NODAGA}-\mathrm{AMBA}$ (Fig. 3D). Overall, ${ }^{64} \mathrm{Cu}-$ NODAGA-RM1 exhibited superior in vivo performance, compared with the ${ }^{64} \mathrm{Cu}-\mathrm{NODAGA}-\mathrm{AMBA}$ probe.

The small-animal PET images and quantification analyses for ${ }^{18} \mathrm{~F}$-AlF-NODAGAAMBA and ${ }^{18} \mathrm{~F}-\mathrm{AlF}-\mathrm{NODAGA}-\mathrm{RM} 1$ are shown in Figures 4 and 5, respectively. As clearly shown in the PET images (Figs. 4A and 5A, top), both probes accumulated rapidly within the tumor, and favorable tumor-to-background imaging contrasts were achieved at $0.5 \mathrm{~h}$ after injection. Furthermore, the coinjection of the unlabeled GRPRtargeting peptide AMBA significantly reduced the uptake of both probes $(P<0.05)$, resulting in significantly reduced tumorto-background contrast in vivo (Figs. 4A and $5 \mathrm{~A}$, bottom). These results clearly demonstrated the excellent in vivo targeting ability and specificity of both probes. Moreover, similar to the ${ }^{64} \mathrm{Cu}$-labeled peptides, ${ }^{18} \mathrm{~F}$-AlF-NODAGA-AMBA exhibited more rapid tumor clearance than ${ }^{18} \mathrm{~F}-\mathrm{AlF}$ NODAGA-RM1 (Figs. 4A and 5A, top). Quantification analysis indicated that the tumor uptake of ${ }^{18} \mathrm{~F}$-AlF-NODAGA-AMBA was $3.7 \pm 0.70,2.4 \pm 0.24$, and $1.4 \pm$ $0.13 \% \mathrm{ID} / \mathrm{g}$ at $0.5,1$, and $2 \mathrm{~h}$, respectively (Fig. 4B), whereas the tumor uptake of ${ }^{18} \mathrm{~F}-\mathrm{AlF}-\mathrm{NODAGA}-\mathrm{RM} 1$ was $4.6 \pm 1.5$, $4.0 \pm 0.87$, and $3.9 \pm 0.48 \% \mathrm{ID} / \mathrm{g}$ at 0.5 , 


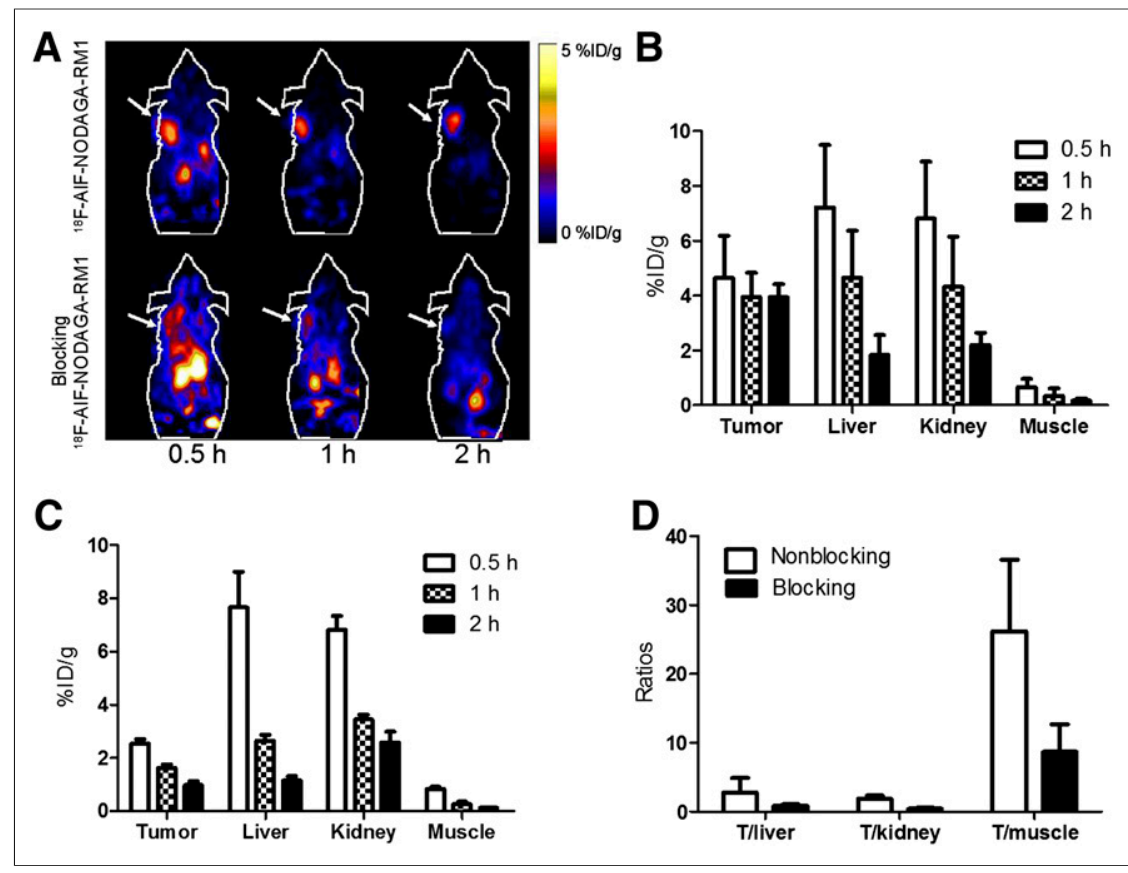

FIGURE 5. (A) Decay-corrected whole-body coronal small-animal PET images of PC3 tumorbearing male nude mice from static scan at $0.5,1$, and $2 \mathrm{~h}$ after injection of ${ }^{18} \mathrm{~F}$-AIF-NODAGARM1 without (top) or with (bottom) AMBA as blocking agent (10 mg/kg of body weight). Tumors are indicated by arrows. (B and C) Small-animal PET quantification of tumors and major organs at $0.5,1$, and $2 \mathrm{~h}$ after injection of ${ }^{18} \mathrm{~F}-\mathrm{AIF}-\mathrm{NODAGA}-\mathrm{RM} 1$ without (B) or with (C) AMBA as blocking agent (10 mg/kg of body weight). (D) Comparison of tumor-to-normal-tissue (muscle, kidney, and liver) ratios of ${ }^{18} \mathrm{~F}$-AIF-NODAGA-RM1 without or with AMBA at $2 \mathrm{~h}$ after injection.
NODAGA-AMBA and $2.5 \pm 0.36,1.6 \pm$ 0.34 , and $0.93 \pm 0.14 \% \mathrm{ID} / \mathrm{g}$ for ${ }^{18} \mathrm{~F}-\mathrm{AlF}-$ NODAGA-RM1 at $0.5,1$, and $2 \mathrm{~h}$ after injection, respectively. Lastly, consistent with their corresponding ${ }^{64} \mathrm{Cu}$-labeled counterparts, both ${ }^{18} \mathrm{~F}-\mathrm{AlF}-\mathrm{NODAGA}-\mathrm{AMBA}$ and ${ }^{18} \mathrm{~F}$-AIF-NODAGA-RM1 were excreted through both the hepatobiliary and the renal systems. Taken together, these results clearly suggest ${ }^{18} \mathrm{~F}$-AlF-NODAGA-RM1 to be a more promising probe than ${ }^{18} \mathrm{~F}$-AlFNODAGA-AMBA.

\section{Biodistribution Studies}

Next, we performed a biodistribution study of ${ }^{64} \mathrm{Cu}-N O D A G A-R M 1$ and ${ }^{18} \mathrm{~F}-\mathrm{AlF}-N O D A G A-$ RM1. The results are shown in Table 1. The tumor uptake for ${ }^{64} \mathrm{Cu}-\mathrm{NODAGA-RM} 1$ at 2 and $24 \mathrm{~h}$ after injection were $4.30 \pm 0.98$ and $2.62 \pm 0.32 \% \mathrm{ID} / \mathrm{g}$, respectively. ${ }^{64} \mathrm{Cu}-$ NODAGA-RM1 also showed relatively low kidney and liver uptake.

Without the presence of AMBA peptide as a blocking agent at $2 \mathrm{~h}$ after injection, the tumor, liver, and kidney uptake for ${ }^{18} \mathrm{~F}$-AlF-NODAGA-RM1 $(\sim 0.37 \mathrm{MBq}$ [10 $\mu \mathrm{Ci}] /$ mouse, $n=5)$ was $5.2 \pm 0.84,2.5 \pm$ 0.96 , and $4.6 \pm 1.9 \% \mathrm{ID} / \mathrm{g}$, respectively. In contrast, the same organ uptake for the blocking group was $1.8 \pm 0.30,1.9 \pm$ 0.19 , and $7.3 \pm 2.1 \% \mathrm{ID} / \mathrm{g}$, which is con1 , and $2 \mathrm{~h}$, respectively (Fig. 5B). At 1 and $2 \mathrm{~h}$ after injection, the tumor uptake of ${ }^{18} \mathrm{~F}$-AlF-NODAGA-RM1 was significantly increased, compared with that of ${ }^{18} \mathrm{~F}$-AlF-NODAGA-AMBA $(P<$ $0.05)$. The coinjection of ${ }^{18} \mathrm{~F}-\mathrm{AlF}-\mathrm{NODAGA}-\mathrm{AMBA}$ or ${ }^{18} \mathrm{~F}-\mathrm{AlF}-$ NODAGA-RM1 with blocking doses of AMBA also significantly reduced their tumor uptake (Figs. $4 \mathrm{~B}$ and $5 \mathrm{~B}$ ). The tumor uptake was $0.66 \pm 0.19,0.55 \pm 0.15$, and $0.39 \pm 0.18 \% \mathrm{ID} / \mathrm{g}$ for ${ }^{18} \mathrm{~F}-\mathrm{AlF}-$ sistent with the PET imaging results. Increased pancreatic uptake in the control tumor mice $(5.1 \pm 1.4 \% \mathrm{ID} / \mathrm{g})$, which is in contrast with reduced pancreatic uptake in the blocking mice $(0.54 \pm 0.13$ $\% \mathrm{ID} / \mathrm{g}$ ), was also observed. Again, the significantly reduced uptake of the probe in the GRPR-positive tissues, including the PC3 tumor and pancreas, confirmed the receptor-targeting specificity of the probes.

TABLE 1

Biodistribution Data of ${ }^{64} \mathrm{Cu}-\mathrm{NODAGA}-\mathrm{RM} 1$ and ${ }^{18} \mathrm{~F}-\mathrm{AIF}-\mathrm{NODAGA}-\mathrm{RM} 1$ in PC3 Tumor-Bearing Mice

\begin{tabular}{lcccc}
\hline Organ & $\begin{array}{c}{ }^{64} \text { Cu-NODAGA-RM1 } \\
(2 \mathrm{~h} \text { after injection })\end{array}$ & $\begin{array}{c}{ }^{64} \text { Cu-NODAGA-RM1 } \\
(24 \mathrm{~h} \text { after injection })\end{array}$ & $\begin{array}{c}\text { 18F-AlF-NODAGA-RM1 } \\
(2 \mathrm{~h} \text { after injection), } \\
\text { nonblocking }\end{array}$ & $\begin{array}{c}\text { 18F-AIF-NODAGA-RM1 } \\
(2 \mathrm{~h} \text { after injection), } \\
\text { blocking }\end{array}$ \\
\hline Blood & $0.17 \pm 0.08$ & $0.06 \pm 0.02$ & $0.51 \pm 0.24$ & $0.57 \pm 0.11$ \\
Heart & $0.22 \pm 0.05$ & $0.16 \pm 0.02$ & $0.42 \pm 0.19$ & $0.48 \pm 0.09$ \\
Lungs & $0.40 \pm 0.21$ & $0.27 \pm 0.08$ & $0.77 \pm 0.29$ & $2.05 \pm 2.64$ \\
Liver & $1.29 \pm 0.56$ & $0.75 \pm 0.15$ & $2.53 \pm 0.96$ & $1.87 \pm 0.19$ \\
Spleen & $0.25 \pm 0.03$ & $0.15 \pm 0.02$ & $0.39 \pm 0.15$ & $0.61 \pm 0.41$ \\
Pancreas & $0.41 \pm 0.20$ & $0.13 \pm 0.05$ & $5.10 \pm 1.44$ & $0.55 \pm 0.13$ \\
Stomach & $0.52 \pm 0.25$ & $0.28 \pm 0.04$ & $0.86 \pm 0.13$ & $1.04 \pm 0.34$ \\
Brain & $0.03 \pm 0.01$ & $0.02 \pm 0.01$ & $0.07 \pm 0.02$ & $0.10 \pm 0.03$ \\
Intestine & $0.37 \pm 0.25$ & $0.17 \pm 0.09$ & $1.68 \pm 1.13$ & $3.60 \pm 1.85$ \\
Kidneys & $1.39 \pm 0.33$ & $0.62 \pm 0.32$ & $4.65 \pm 1.95$ & $7.32 \pm 2.09$ \\
Skin & $0.29 \pm 0.08$ & $0.13 \pm 0.05$ & $0.95 \pm 0.50$ & $2.44 \pm 2.48$ \\
Muscle & $0.09 \pm 0.04$ & $0.03 \pm 0.02$ & $0.36 \pm 0.16$ & $0.42 \pm 0.13$ \\
Bone & $0.19 \pm 0.05$ & $0.07 \pm 0.07$ & $1.58 \pm 0.52$ & $1.68 \pm 0.34$ \\
Tumor & $4.30 \pm 0.98$ & $2.62 \pm 0.32$ & $5.25 \pm 0.84$ & $1.86 \pm 0.30$
\end{tabular}

Data are expressed as normalized accumulation of activity in \% ID/g $\pm \operatorname{SD}(n=5)$. 


\section{DISCUSSION}

In this study, 2 important BBN peptides, AMBA and RM1, were labeled with ${ }^{18} \mathrm{~F}$ and used for PET imaging of PCa for the first time. These 2 peptides were first modified with the chelator NODAGA to render the bioconjugates more easily labeled with ${ }^{64} \mathrm{Cu}$ and ${ }^{18} \mathrm{~F}-$ AlF to form stable radiocomplexes. After modification with NODAGA, the half maximal inhibitory concentration of each of the conjugated peptides was still within the nanomolar range (Fig. 2). Therefore, they were further radiolabeled with ${ }^{64} \mathrm{Cu}$ and ${ }^{18} \mathrm{~F}-\mathrm{AlF}$ and tested in vivo.

The radiolabeling of NODAGA-AMBA and NODAGA-RM1 with ${ }^{64} \mathrm{Cu}$ is a relatively simple and straightforward process. Al-F chelation chemistry has been used for ${ }^{18} \mathrm{~F}$ labeling, as pioneered by McBride et al., and this strategy has many advantages, such as short labeling time and water compatibility (31). We previously synthesized ${ }^{18} \mathrm{~F}-\mathrm{AlF}-\mathrm{NOTA}-\mathrm{RGD}_{2}$ as a PET probe for tumor angiogenesis imaging (33). The favorable in vivo performance of several ${ }^{18} \mathrm{~F}$-AlF-labeled peptides reported thus far, together with their short routes of radiosynthesis, highlight the potential accelerated clinical translation of ${ }^{18} \mathrm{~F}$-labeled peptides using this novel radiofluorination strategy. Thus, we explored this straightforward, single-step and powerful labeling strategy to radiofluorinate AMBA and RM1. Interestingly, compared with the yield produced by the ${ }^{18} \mathrm{~F}-\mathrm{AlF}$ radiolabeling of NOTA-RGD $2(17.9 \%)$, the yields produced by NODAGA-RM1 and NODAGA-AMBA were approximately $5 \%$ decay-corrected, which was likely caused by the different chelating moieties used (36). But these labeling yields are still sufficient for producing enough PET probes for further in vitro and in vivo evaluation.

According to the in vitro serum stability assay and in vivo imaging results, both the ${ }^{64} \mathrm{Cu}$ - and the ${ }^{18} \mathrm{~F}$-labeled NODAGA-AMBA probes were less stable than the NODAGA-RM1 probes. Moreover, the ${ }^{64} \mathrm{Cu}$ - and ${ }^{18} \mathrm{~F}$-labeled NODAGA-RM1 probes exhibited more favorable in vivo tumor retention and imaging quality than the ${ }^{64} \mathrm{Cu}$ - and ${ }^{18} \mathrm{~F}$-labeled NODAGA-AMBA probes (Figs. 3-5). BBN peptide antagonists and agonists exhibited different stabilities and in vivo behavior. Schroeder et al. reported that the antagonist demobesin-1 exhibits superior in vivo stability, increased tumor uptake and retention, and faster pancreatic and renal clearance than the other 4 GRPR agonists (37). Mansi et al. also compared the performance of the radioantagonist ${ }^{111} \mathrm{In}$-RM1 with the radioagonist ${ }^{111}$ In-AMBA (24). ${ }^{111}$ In-RM1 demonstrated relatively lower affinity for GRPR but more favorable pharmacokinetics and targeting properties, as supported by increased tumor uptake and tumor-to-normal-tissue ratios. ${ }^{111} \mathrm{In}$-RM1 appeared to be superior to AMBA for in vivo SPECT imaging and for the targeted radiotherapy of GRPR-positive tumors. Consistent with these findings, our study using ${ }^{64} \mathrm{Cu}$ and ${ }^{18} \mathrm{~F}$-AlF demonstrated that antagonist RM1-based PET probes exhibit significantly increased stability and more optimal imaging performance than the agonist AMBAbased probes.

Recently, NOTA-8-Aoc-BBN(7-14)- $\mathrm{NH}_{2}$ was labeled with ${ }^{18} \mathrm{~F}$ using the $\mathrm{Al}^{18} \mathrm{~F}$ method described by Dijkgraaf et al., and the results showed that the AlF method does not affect the in vivo behavior of the peptide (38). For example, the uptake of ${ }^{18} \mathrm{~F}$-labeled NOTA-8-Aoc-BBN(7-14)- $\mathrm{NH}_{2}$ in the PC3 tumors was $2.15 \pm 0.55$ $\% \mathrm{ID} / \mathrm{g}$, which is similar to the ${ }^{64} \mathrm{Cu}$-labeled NOTA-8-Aoc-BBN(714) conjugate $(3.59 \pm 0.70 \% \mathrm{ID} / \mathrm{g})$ at $1 \mathrm{~h}$ after injection (18). In our study, ${ }^{18} \mathrm{~F}$-AlF-NODAGA-RM1 also exhibited uptake similar to ${ }^{64} \mathrm{Cu}$-NODAGA-RM1 $(4.6 \pm 1.5$ vs. $3.3 \pm 0.38$ at $0.5 \mathrm{~h}$ and $4.0 \pm 0.87$ vs. $3.0 \pm 0.76$ at $1 \mathrm{~h}$, respectively). More importantly,
${ }^{18} \mathrm{~F}-\mathrm{AlF}-\mathrm{NODAGA}-\mathrm{RM} 1$ exhibited increased tumor uptake, compared with ${ }^{18} \mathrm{~F}$-AlF-NOTA-8-Aoc-BBN (7-14) $\mathrm{NH}_{2}(4.0 \pm 0.87$ vs. $2.15 \pm 0.55)$, highlighting the advantages of using RM1 for PET probe development. Taken together, on the basis of their favorable in vitro serum stability and in vivo tumor imaging properties (Figs. 3 and 5), ${ }^{64} \mathrm{Cu}$-NODAGA-RM1 and ${ }^{18} \mathrm{~F}-\mathrm{AlF}-$ NODAGA-RM1 warrant further investigation for clinical translation. In particular, the radioantagonist ${ }^{18} \mathrm{~F}$-AlF-NODAGA-RM1 demonstrated wide availability, easy radiosynthesis, increased tumor uptake, and tumor-to-background contrast. Moreover, considering the different physical properties and availability of ${ }^{64} \mathrm{Cu}$ and ${ }^{18} \mathrm{~F},{ }^{18} \mathrm{~F}$-AlF-NODAGA-RM1 holds significant promise for imaging $\mathrm{PCa}$ in clinical applications.

\section{CONCLUSION}

NODAGA-RM1 and NODAGA-AMBA have been successfully prepared and radiolabeled with ${ }^{64} \mathrm{Cu}$ and ${ }^{18} \mathrm{~F}$. The radiolabeling methods are simple and straightforward. In vitro assay and in vivo studies showed that ${ }^{64} \mathrm{Cu}$ - and ${ }^{18} \mathrm{~F}$-labeled NODAGA-AMBA are limited by certain undesirable properties, such as relatively low stability and rapid tumor clearance. However, both ${ }^{64} \mathrm{Cu}-\mathrm{NODAGA}-$ RM1 and ${ }^{18} \mathrm{~F}$-AlF-NODAGA-RM1 exhibit excellent in vitro serum stability and in vivo tumor imaging properties. In particular, ${ }^{18} \mathrm{~F}$ AlF-NODAGA-RM1 exhibited increased tumor uptake and favorable pharmacokinetics, representing a highly promising probe for the PET imaging of $\mathrm{PCa}$ in clinical applications.

\section{DISCLOSURE}

The costs of publication of this article were defrayed in part by the payment of page charges. Therefore, and solely to indicate this fact, this article is hereby marked "advertisement" in accordance with 18 USC section 1734 . This work was partially supported by DOD-PCRP-NIA PC094646, NCI 5R01 CA119053, and the In vivo Cellular Molecular Imaging Center (ICMIC) grant P50 CA114747. No other potential conflict of interest relevant to this article was reported.

\section{REFERENCES}

1. Siegel R, Naishadham D, Jemal A. Cancer statistics, 2012. CA Cancer J Clin. 2012;62:10-29.

2. Grant K, Lindenberg ML, Shebel H, et al. Functional and molecular imaging of localized and recurrent prostate cancer. Eur J Nucl Med Mol Imaging. 2013;40 (suppl 1):S48-59.

3. Jana S, Blaufox MD. Nuclear medicine studies of the prostate, testes, and bladder. Semin Nucl Med. 2006;36:51-72.

4. Bouchelouche K, Oehr P. Positron emission tomography and positron emission tomography/computerized tomography of urological malignancies: an update review. J Urol. 2008;179:34-45.

5. Larson SM, Schoder H. Advances in positron emission tomography applications for urologic cancers. Curr Opin Urol. 2008;18:65-70.

6. Oehr P, Bouchelouche K. Imaging of prostate cancer. Curr Opin Oncol. 2007; 19:259-264.

7. Schöder H, Larson SM. Positron emission tomography for prostate, bladder, and renal cancer. Semin Nucl Med. 2004;34:274-292.

8. Delgado Bolton RC, Mucientes Rasilla J, Perez Castejon MJ, Carreras Delgado JL. Positron emission tomography (PET) and PET-CT in renal, bladder and prostate cancer: update [in Spanish]. Actas Urol Esp. 2009;33:11-23.

9. Markwalder R, Reubi JC. Gastrin-releasing peptide receptors in the human prostate: relation to neoplastic transformation. Cancer Res. 1999;59:1152-1159.

10. Jensen RT, Battey JF, Spindel ER, Benya RV. International Union of Pharmacology. LXVIII. Mammalian bombesin receptors: nomenclature, distribution, pharmacology, signaling, and functions in normal and disease states. Pharmacol Rev. 2008;60:1-42.

11. Gugger M, Reubi JC. Gastrin-releasing peptide receptors in non-neoplastic and neoplastic human breast. Am J Pathol. 1999;155:2067-2076. 
12. Bostwick DG, Roth KA, Evans CJ, Barchas JD, Bensch KG. Gastrin-releasing peptide, a mammalian analog of bombesin, is present in human neuroendocrine lung tumors. Am J Pathol. 1984;117:195-200.

13. Johnson CV, Shelton T, Smith CJ, et al. Evaluation of combined ${ }^{177}$ Lu-DOTA-8AOC-BBN (7-14) $\mathrm{NH}_{2}$ GRP receptor-targeted radiotherapy and chemotherapy in PC-3 human prostate tumor cell xenografted SCID mice. Cancer Biother Radiopharm. 2006;21:155-166.

14. Smith CJ, Volkert WA, Hoffman TJ. Radiolabeled peptide conjugates for targeting of the bombesin receptor superfamily subtypes. Nucl Med Biol. 2005;32:733-740.

15. Ananias HJ, de Jong IJ, Dierckx RA, van de Wiele C, Helfrich W, Elsinga PH. Nuclear imaging of prostate cancer with gastrin-releasing-peptide-receptor targeted radiopharmaceuticals. Curr Pharm Des. 2008;14:3033-3047.

16. Abd-Elgaliel WR, Gallazzi F, Garrison JC, et al. Design, synthesis, and biological evaluation of an antagonist-bombesin analogue as targeting vector. Bioconjug Chem. 2008;19:2040-2048.

17. Garrison JC, Rold TL, Sieckman GL, et al. Evaluation of the pharmacokinetic effects of various linking group using the In-111-DOTA-X-BBN(7-14)NH2 structural paradigm in a prostate cancer model. Bioconjug Chem. 2008;19:1803-1812.

18. Prasanphanich AF, Nanda PK, Rold TL, et al. [ ${ }^{64} \mathrm{Cu}-\mathrm{NOTA}-8-A o c-B B N(7-14)$ $\mathrm{NH} 2]$ targeting vector for positron-emission tomography imaging of gastrin-releasing peptide receptor-expressing tissues. Proc Natl Acad Sci USA. 2007;104:12462-12467.

19. Xu Y, Huang W, Ren G, et al. A four-arma star-shaped poly(ethylene glycol) (StarPEG) platform for bombesin peptide delivery to gastrin-releasing peptide receptors in prostate cancer. ACS Macro Letters. 2012;1:753-757.

20. Graham MM, Menda Y. Radiopeptide imaging and therapy in the United States. J Nucl Med. 2011;52(suppl 2):56S-63S.

21. Ambrosini V, Fani M, Fanti S, Forrer F, Maecke HR. Radiopeptide imaging and therapy in Europe. J Nucl Med. 2011;52(suppl 2):42S-55S.

22. Ait-Mohand S, Fournier P, Dumulon-Perreault V, et al. Evaluation of ${ }^{64} \mathrm{Cu}$-labeled bifunctional chelate-bombesin conjugates. Bioconjug Chem. 2011;22:1729-1735.

23. Lantry LE, Cappelletti E, Maddalena ME, et al. ${ }^{177} \mathrm{Lu}-\mathrm{AMBA}$ : Synthesis and characterization of a selective ${ }^{177}$ Lu-labeled GRP-R agonist for systemic radiotherapy of prostate cancer. J Nucl Med. 2006;47:1144-1152.

24. Mansi R, Wang X, Forrer F, et al. Evaluation of a 1,4,7,10-tetraazacyclododecane1,4,7,10-tetraacetic acid-conjugated bombesin-based radioantagonist for the labeling with single-photon emission computed tomography, positron emission tomography, and therapeutic radionuclides. Clin Cancer Res. 2009;15:5240-5249.

25. Schroeder RP, van Weerden WM, Krenning EP, et al. Gastrin-releasing peptide receptor-based targeting using bombesin analogues is superior to metabolism-based targeting using choline for in vivo imaging of human prostate cancer xenografts. Eur J Nucl Med Mol Imaging. 2011;38:1257-1266.

26. Ho CL, Liu IH, Wu YH, et al. Molecular imaging, pharmacokinetics, and dosimetry of In-AMBA in human prostate tumor-bearing mice. J Biomed Biotech. 2011;2011: 101497.

27. Lane SR, Nanda P, Rold TL, et al. Optimization, biological evaluation and microPET imaging of copper-64-labeled bombesin agonists, [Cu-64-NO2A(X)-BBN(7-14)NH2], in a prostate tumor xenografted mouse model. Nucl Med Biol. 2010;37:751-761.

28. Maddalena ME, Fox J, Chen J, et al. ${ }^{177} \mathrm{Lu}-\mathrm{AMBA}$ biodistribution, radiotherapeutic efficacy, imaging, and autoradiography in prostate cancer models with low GRP-R expression. J Nucl Med. 2009;50:2017-2024.

29. Anderson CJ, Ferdani R. Copper-64 radiopharmaceuticals for PET imaging of cancer: advances in preclinical and clinical research. Cancer Biother Radiopharm. 2009;24:379-393.

30. Laverman P, McBride WJ, Sharkey RM, et al. A novel facile method of labeling octreotide with ${ }^{18}$ F-fluorine. J Nucl Med. 2010;51:454-461.

31. McBride WJ, D'Souza CA, Sharkey RM, et al. Improved ${ }^{18} \mathrm{~F}$ labeling of peptides with a fluoride-aluminum-chelate complex. Bioconjug Chem. 2010;21:13311340 .

32. McBride WJ, Sharkey RM, Karacay H, et al. A novel method of ${ }^{18} \mathrm{~F}$ radiolabeling for PET. J Nucl Med. 2009;50:991-998.

33. Liu S, Liu H, Jiang H, Xu Y, Zhang H, Cheng Z. One-step radiosynthesis of ${ }^{18} \mathrm{~F}-$ AlF-NOTA-RGD 2 for tumor angiogenesis PET imaging. Eur J Nucl Med Mol Imaging. 2011;38:1732-1741.

34. Jiang L, Kimura RH, Miao Z, et al. Evaluation of a ${ }^{64} \mathrm{Cu}$-labeled cystine-knot peptide based on agouti-related protein for PET of tumors expressing alphavbeta3 integrin. J Nucl Med. 2010;51:251-258.

35. Yang M, Gao H, Zhou Y, et al. ${ }^{18}$ F-Labeled GRPR agonists and antagonists: a comparative study in prostate cancer imaging. Theranostics. 2011;1:220-229.

36. D'Souza CA, McBride WJ, Sharkey RM, Todaro LJ, Goldenberg DM. Highyielding aqueous ${ }^{18} \mathrm{~F}$-labeling of peptides via $\mathrm{Al}^{18} \mathrm{~F}$ chelation. Bioconjug Chem. 2011;22:1793-1803.

37. Schroeder RP, Muller C, Reneman S, et al. A standardised study to compare prostate cancer targeting efficacy of five radiolabelled bombesin analogues. Eur J Nucl Med Mol Imaging. 2010;37:1386-1396.

38. Dijkgraaf I, Franssen GM, McBride WJ, et al. PET of tumors expressing gastrinreleasing peptide receptor with an ${ }^{18} \mathrm{~F}$-labeled bombesin Analog. J Nucl Med. 2012;53:947-952. 